\title{
Policy Options for Reducing Water for Agriculture in Saudi Arabia
}

Christopher Napoli, Ben Wise, David Wogan, Lama Yaseen 


\section{About KAPSARC}

The King Abdullah Petroleum Studies and Research Center (KAPSARC) is a non-profit global institution dedicated to independent research into energy economics, policy, technology, and the environment across all types of energy. KAPSARC's mandate is to advance the understanding of energy challenges and opportunities facing the world today and tomorrow, through unbiased, independent, and high-caliber research for the benefit of society. KAPSARC is located in Riyadh, Saudi Arabia.

\section{Legal Notice}

(C) Copyright 2016 King Abdullah Petroleum Studies and Research Center (KAPSARC). No portion of this document may be reproduced or utilized without the proper attribution to KAPSARC. 


\section{Key Points}

audi Arabia relies almost exclusively on aquifers and desalination to provide its water. Roughly 87 percent of these water extractions are used for agriculture, and so any policy to improve the sustainability of water resources cannot ignore this agriculture dimension.

Our study identified a range of scenarios in which water intensive, low-value-added crops were substituted with water productive, high-value-added crops.

A 47 percent reduction in agricultural water consumption could be achieved without compromising food security or aggregate farmer revenues. Notably, this scenario minimizes social and political disruption.

In the most extreme case, water for agriculture could be reduced by 70 percent - the highest water savings identified among the 28 scenarios - but at the expense of losing sectors including dairy, fodder and grains.

Reductions in water use for agriculture are more likely to be acceptable when harmonized with broader social objectives and this study shows that this can be done. It lays out the different options available and offers suggestions for how to maximize water reductions at the lowest social cost. 


\section{Summary}

audi Arabia is an extremely water scarce country. In this desert Kingdom about

87 percent of water extracted is used for agriculture, and, as such, no policy to improve the sustainability of water resources can ignore the agriculture dimension. The benefits are not restricted to water savings alone. Reducing water consumption could lead to significant energy savings, particularly when the water saved is used to displace desalinated water.

We constructed a linear program to analyze the tradeoffs in water consumption within the agriculture and livestock sectors under a range of policy scenarios. We explored how crop substitution can reduce aggregate water use without compromising the current level of food security or aggregate farmer revenues. The effects of each scenario on total water use, total energy used to meet water demand and the diversity of crops produced are examined. We also built a collective choice model that estimates the balance of influence implied by announced policy preferences to evaluate the most pragmatic policy choices. Thus, we generated 28 scenarios and selected the results from the 10 most viable choices for discussion in this paper.

A key finding was that water savings of 47 percent could be achieved while retaining a broad slate of agricultural products and, according to our analysis, this was the least socially and politically disruptive scenario studied. This is well above the Ministry of Agriculture's stated objective to reduce water use by 30 percent by 2030. It shows that a diverse supply of crops can be produced domestically while achieving significant reductions in water use.

In an extreme case, water for agriculture could potentially be reduced by as much as 70 percent without compromising food security or aggregate farmer revenues. However, in this scenario certain sectors such as diary, fodder and grains were eliminated leading to a limited portfolio.

The results show that if water usage is to be minimized while maintaining food production and farmer revenues, then the primary candidates for reduction are crops or livestock with high-water intensity and low revenue and/or output. These include fodder and wheat. Eliminating them would actually yield higher water savings than moderate cuts across a larger portfolio of crops at the lowest social cost.

Future analysis could explore the role of input prices and government subsidies for crop production choices. Furthermore, our research uncovered a lack of consensus around how countries define food security. There would be value in understanding how uncertainty of agricultural supply relates to uncertainty of food security outcome and which policies achieve the largest impact on the latter. 


\section{Introduction}

W ater scarcity is typically defined as the ratio between a country's total freshwater withdrawals and its total renewable water resources (Brown \& Matlock 2011). When a country withdraws less than 20 percent of its total renewable water resources it is considered to be water abundant. If extraction falls between 20 percent and 40 percent, it is considered water scarce; and when the ratio exceeds 40 percent, a country is considered severely water scarce. By this definition, Saudi Arabia is a severely water scarce country as it is withdrawing an astounding 1,056 percent (own calculations, data from Aquastat database, 2015) of its total renewable water resources, meaning the country is not only relying on renewable water resources, but is also drawing heavily from its nonrenewable fossil aquifers.

While Saudi Arabia has always faced a certain level of water scarcity, consumption levels were not always this high. In 1975, the first year for which water extraction data is available, Saudi Arabia withdrew $1.75 \mathrm{~km}^{3}$ of water. This figure ballooned to $25 \mathrm{~km}^{3}$ by 2006 (Aquastat database 2015). The increase in water consumption was the result of two factors. First, the population of the country increased dramatically between 1975 and 2006 from 7.4 million to 25.4 million (World Bank, 2015). Second, windfall profits from oil exports in the 1970s were used to finance large expansions of many sectors in the economy, notably agriculture. Today, agriculture consumes about 87 percent of all extracted water. As figure 1 shows, 31 percent of the water extracted is used to produce alfalfa and other fodder, which provide feed for the meat and dairy industries. Fruits (including dates), vegetables and cereals (including wheat) consume 35 percent of all water for agriculture. Given the percentage of water used for agriculture any attempt at improving the sustainability of water resources needs to include a reduction in agriculture consumption.
Saudi Arabia's extreme water scarcity makes it a sub-optimal location for agricultural production. Despite this, the rationale for supporting a domestic agriculture industry is twofold. First, the country is attempting to safeguard its food security by ensuring that an adequate amount of diverse foods are produced locally (Lippman 2010). For certain fruit, vegetables and cereals, food self-sufficiency goals were met and the country exports surplus production (Al-Shayaa 2012). At the aggregate level, however, results are varied. Self-sufficiency levels (i.e., the ratio of domestic production to overall consumption) differ for a number of produce: vegetables (88 percent); fruit (57.4 percent); meats (41.2 percent) and cereals (7.4 percent) (Ministry of Agriculture 2012). While these self-sufficiency levels exceed other Gulf countries, they are lower than much of the Middle East and North African (MENA) region (Sadik, El-Solh \& Saab 2014). At the aggregate level, FAOSTAT (2015) estimates that Saudi Arabia's total agriculture self-sufficiency ratio is roughly 25 percent.

\section{The Food and Agriculture Organization (FAO)} defines food security as "a situation that exists when all people, at all times, have physical, social and economic access to sufficient, safe and nutritious food that meets their dietary needs and food preferences for an active and healthy life" (FAO 2002). From the perspective of a country like Saudi Arabia, food security is more of a risk-management issue than a structural inability to meet the needs of families-the problem in many low-income nations. While there is an ongoing discussion on how best to define food security - including the reliability of a country's food imports from abroad - we use domestic food production as a benchmark as this is a measure chosen by the Saudi government.

A country can provide its population with food security in several ways. The most direct way is 


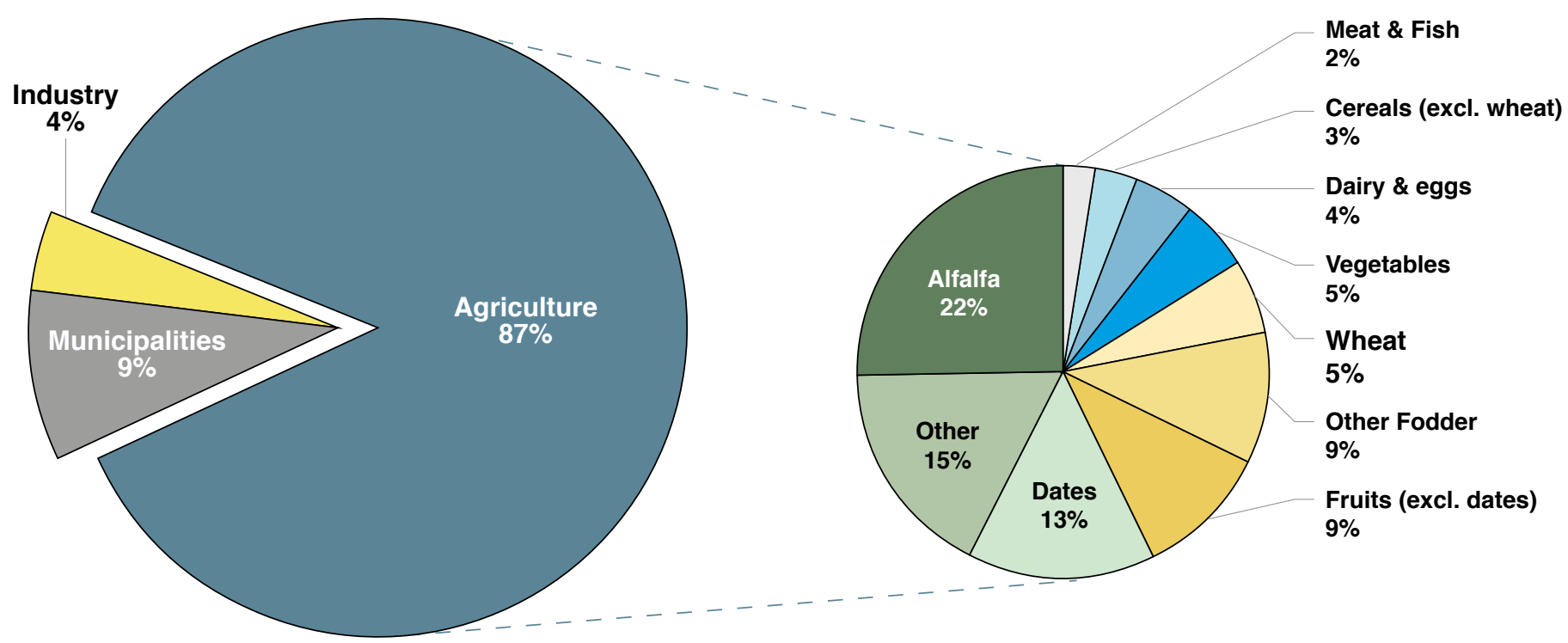

Figure 1. Extracted water use in Saudi Arabia, 2010

Source: FAO (2015), Min. of agriculture (2015)

to support domestic production. Alternatively, it can import agriculture products from a diverse portfolio of suppliers from different parts of the world. While diversifying supply may increase costs over purchasing large quantities at discounts, this strategy would protect against production problems in a single country or shipping disruptions. A country could build a strategic reserve of storable crops. Additionally, food security can be improved through purchasing agriculture land or agri-food companies located abroad in order to influence the direction of food trade. Saudi Arabia has engaged in the first and last methods: the country has bought working farms in Poland and the Ukraine through the Saudi Agricultural and Livestock Investment Co. (SALIC), and in 2015 the country became a large investor in the Canadian Wheat Board. Despite costeffective alternatives, there is still the presumption that a certain share of Saudi Arabian agriculture production should be produced domestically, which is why this paper focuses on options for achieving this domestic production while reducing water use.

The second reason for supporting domestic agriculture production is that, as with much of the world, the agriculture industry is politically and socially sensitive (Sen 1982; Moench 2002). This industry provides employment and income, particularly in rural regions, and certain agricultural products, such as dates, are culturally significant. The government supports the agriculture industry with a range of implicit and explicit subsidies to make the industry profitable, despite the fact that it may be unsustainable in the long term. Examples of subsidies include the following: interest free loans and grants to farmers by the Saudi Arabian Agricultural Bank; government subsidies for livestock and poultry feed as well as farm machinery and equipment; government funding to support research aimed at developing new crop strains with greater 
resistance to pests; government expenditures to improve roads linking producers with consumer markets; effectively no tariff on water and very low tariffs on energy; and commodity boards such as the Grain Silos and Flour Mills Organization that agree to purchase grains and cereals at guaranteed prices irrespective of international market prices (Mousa 2015). The effects of these types of market distortions are seen in the difference between the price at which certain commodities are sold and their true cost of production. For example, the water required for a 1 riyal loaf of bread costs 2 riyals to produce (Vincent 2008).

Government intervention in setting prices is not unique to the agriculture sector. Other sectors that are important to the country, like the power and water sectors, experience both administered prices for fuel inputs and regulated prices for electricity and water. These market distortions lead to investment in less efficient power and water infrastructure, and high domestic consumption of resources.

The quest for food self-sufficiency has had negative effects on the sustainability of groundwater resources (Al-Shayaa 2012). The government recognizes the unsustainability of current trends and has responded with two government policies. First, the Council of Ministers Resolution No. 335 of 19 November 2007 mandated the phasing out of domestic wheat production by 2016. It also abolished import tariffs on cereals, animal feed and wheat flour, and reduced the general tariff on foodstuffs from 75 percent to 5 percent (Woertz 2013; World Trade Organisation 2011). Second, in 2010 the Ministry of Agriculture set a target of a 30 percent reduction in water usage in the agriculture sector by 2030 through improving irrigation techniques and eliminating water intensive crops, and this target may be increased to 50 percent (Jeffreys 2011).

We use a simple linear program model to explore the different ways the Ministry of Agriculture might meet its water reduction objectives without further compromising food security or farmer revenues. The results suggest that there are a number of options for reducing agricultural consumption by the 30 percent and 50 percent objectives, but in each case, certain large water intensive crops must be substantially reduced or eliminated. For each option, the water reductions lead to energy savings, with the amount of energy saved being a function of where the actual water reductions occur.

Building on these findings, we explore the potential social implications of the portfolio of crops produced under the different water reduction strategies.

The results suggest that socially palatable options exist and, in some cases, it may be more socially acceptable to eliminate a few large, water intensive, low-value added crops than to reduce several medium-value added crops. 


\section{Description of Data and Model}

\section{Data Sources}

Table A-1 in the Appendix contains data on the production of crop and livestock goods, water footprint and monetary value of goods in Saudi Arabia. The data were compiled from reports by the Ministry of Agriculture, the United Nations Food and Agriculture Organization (FAO) and the Arab Organization for Agricultural Development for 2013 (FAOSTAT 2015; AOAD 2015).

Blue water footprint values (Mekonnen \& Hoekstra 2012) were used to calculate the irrigated water used to produce the respective agricultural products. Due to missing water-footprint data for some products, assumptions were made by either using aggregate data or extrapolating water footprints from countries with comparable climates and growing conditions.

\section{Water Minimization Model Description}

We constructed a linear program to analyze the tradeoffs in water consumption in the agriculture and livestock sectors for a range of policy scenarios. We chose a linear programming model as a first-order assessment of how the agriculture system balances three primary components: water consumption; revenue; and total quantity produced. Data for these components are readily available at the national aggregate level and provide sufficient insight into the effect of different crop portfolios on water consumption. Because there are many subsidies to ensure that products sell at desired prices, rather than at competitive market prices, we did not consider input prices as part of the decision to produce a crop or not. A second-order assessment might use a mixed complementarity problem (MCP) to model prices and quantities, which are allowed to adjust somewhat, within administered ranges. An MCP approach has been used to investigate the role of industrial input prices for the power and water sectors (Matar 2015). A similar formulation could be applied to Saudi Arabia's agriculture sector.

The model covers roughly 80 percent of all water used by the agriculture sector. The objective is to minimize water consumption while maintaining producer revenues (aggregate monetary value of all goods produced), while not compromising food security (measured in terms of total tonnage of all goods produced).

The objective function minimizes water consumption:

$$
\min _{W}=\sum_{i}\left(Q_{i} * w_{i}\right)
$$

where $Q_{i}$ is the production quantity in tons of crop $i$ and $w_{i}$ is the water use per ton of crop $i$ produced. Baseline quantities and prices are $Q_{i}^{0}$ and $P_{i}^{0}$. Two constraints require a minimum level of farm revenue (2) and a minimum total production (3):

$$
\begin{gathered}
\sum_{i}\left(Q_{i}^{0} * P_{i}^{0}\right) \leq \sum_{i}\left(Q_{i} * P_{i}\right) \\
\sum_{i} Q_{i}^{0} \leq \sum_{i} Q_{i}
\end{gathered}
$$

where $P_{i}$ represents the price paid to farmers per ton of crop $i$ in constant 2005 USD and $Q_{i}$ represents the volume. The next three constraints set limits on the production of individual crops. Two constraints limit production increases and decreases from 2013 levels (equations 4 and 5 ) and a third requires the production of fodder to supply livestock demand (equation 6).

$$
\begin{gathered}
\left(1-r_{i}\right) * Q_{i}^{0} \leq Q_{i} \\
Q_{i} \leq\left(1+g_{i}\right) * Q_{i}^{0} \\
\sum_{\text {fodder }}\left(Q_{\text {fodder }} * f\right) \geq \sum_{\text {livestock }} Q_{\text {livestock }}
\end{gathered}
$$


The terms $r_{i}$ and $g_{i}$ are the rate of decrease and increase for individual crops and are defined in the different scenarios.

Three crops are used as fodder for livestock: alfalfa, clover, and other forage crops including those produced in small quantities. The ratio of fodder to livestock (including dairy goods) is fixed, such that an increase in livestock production would require an increase in fodder for that livestock. The ratio of livestock to fodder, $f$, was calculated from the current baseline ratio (100 tons of fodder to produce 81 tons of livestock).

An alternate fodder to livestock ratio was calculated for the scenario where 400,000 tons per year of fodder currently grown domestically by Almarai (Almarai Farming Division 2010) are imported. This scenario was chosen because of recent policies by the firm to move away from a reliance on domestically grown fodder. With planned import increases, the new ratio becomes 91 tons of livestock for 100 tons of fodder.

The model reaches a water-minimizing solution by choosing crops with the most weight per cubic meter of water until they reach their individual upper limits (by maximizing production of the most valuable goods in USD per cubic meter of water required).

\section{Policy Scenarios}

We designed a set of scenarios to analyze the tradeoffs in water consumption for different production portfolios. Initially, we considered 28 scenarios to explore the sensitivity of water consumption under different constraints. For this paper, we discuss 10 scenarios that best illustrate the behavior of the modeled agriculture system without creating redundant, overlapping scenarios.

Table 1: Policy Scenarios for Linear Programming Model

\begin{tabular}{|c|c|c|c|c|c|c|}
\hline Scenario & $\begin{array}{c}\text { Production } \\
\text { decrease }\end{array}$ & $\begin{array}{l}\text { Production } \\
\text { increase }\end{array}$ & $\begin{array}{l}\text { Fodder } \\
\text { requirement }\end{array}$ & Wheat & Dairy & Dates \\
\hline 1 & 25 percent & 100 percent & 0.81 & Variable & Variable & Variable \\
\hline 2 & 25 percent & 100 percent & 0.91 & Eliminated & Variable & Fixed \\
\hline 3 & 25 percent & 100 percent & 0.81 & Eliminated & Variable & Variable \\
\hline 4 & 25 percent & 100 percent & 0.91 & Eliminated & Variable & Variable \\
\hline 5 & 25 percent & 100 percent & No requirement & Eliminated & Variable & Variable \\
\hline 6 & 75 percent & 200 percent & 0.81 & Eliminated & Variable & Fixed \\
\hline 7 & 25 percent & 100 percent & Eliminated & Eliminated & Variable & Fixed \\
\hline 8 & 95 percent & 300 percent & No requirement & Eliminated & Variable & Fixed \\
\hline 9 & 75 percent & 300 percent & No requirement & Eliminated & Variable & Variable \\
\hline 10 & 95 percent & 300 percent & Eliminated & Eliminated & Eliminated & Variable \\
\hline
\end{tabular}


As crops that have high water intensity per ton are removed from production, less water-intensive crops are produced to meet the revenue and food security needs. For this reason, we set limits on changes in production under each policy scenario, thus constraining the extent of changes to the overall portfolio of goods. Depending on the policy being tested, individual goods (or groups of goods such as dairy products) are allowed to increase or decrease a given amount by changing the variables $r_{i}$ and $g_{i}$. For example, goods can be eliminated completely (e.g., wheat) by setting $r_{i}=1$ or required to remain the same (e.g., dates) by setting $r_{i}=0$.

There are four options to meet the fodder requirement. The fodder to livestock ratio is set at either 0.81 or 0.91 to represent domestic production or domestic production plus imports of fodder (as in scenarios $1-4,6)$. In the third case there is no requirement for fodder, meaning the ratio does not hold, but the model can produce fodder if it chooses (scenarios 5, 8, and 9). Finally, a scenario where fodder is eliminated means that fodder production is fixed to zero (scenarios 7 and 10).

For wheat, dairy, and dates, there are three options available: fixed, variable and eliminated. A crop cannot increase or decrease in production if it is fixed. If a crop is variable, its production is allowed to vary within the production bounds set in the model, just like any other crop. Production is fixed to zero if a crop is eliminated. 


\section{Results}

number of options can reduce water usage in agriculture without compromising food security or aggregate farmer revenues. Specifically, the results offer four insights. First, Figures 2 and 3 demonstrate that water usage can be reduced by roughly 15 percent (or $3 \mathrm{~km}^{3}$ ) with only minimal changes in the portfolio of crops produced, as demonstrated by scenario 1 . In this scenario, production of dairy and fodder products are slightly reduced and replaced by higher-valueadded vegetables and fruit. This scenario, however, likely understates the potential for water reductions as it does not include Saudi Arabia's commitment to eliminate wheat production by 2016 . When the elimination of wheat is included, as is the case in scenario 3, water savings rise to 20 percent.

Second, the results show that meeting the 30 percent water reduction objective requires a more ambitious strategy, such as those offered by scenarios 6 through 10. In each of these scenarios, at least one of two changes is required: there must either be large changes in the quantities of the crops produced; and/or some of the highly water-intensive crops must be eliminated. It should be noted that scenarios 6 through 10 result in some significant changes to the portfolio of crops produced. For example, in scenario 6 fodder and dairy production are substantially reduced while vegetable production more than doubles. In scenarios 8 and 9, dairy production increases substantially while all other production is reduced.

Third, the potential 50 percent water-reduction target is possible only with substantial changes in crop production and the elimination of water intensive crops. For example, scenario 8 requires the elimination of wheat and substantial reductions in fodder, while scenario 10 requires the removal of wheat, fodder and dairy. In practical terms, both substantial reductions and elimination yield the same result for water intensive crops, as the model will reduce those crops to the maximum allowable limit. For example, in scenario 8 alfalfa is reduced by 95 percent while in scenario 9 it is reduced by 100 percent. Thus, the elimination (or virtual elimination) of these high-water-intensive crops is a prerequisite for large water savings.

Last, the results show that large reductions in water can be achieved through different combinations of crops. In scenarios 8 and 9, the portfolio is dominated by dairy production at the expense of meat and fruits, while in scenario 10 dairy is eliminated and vegetables, meat and fruit make up the total portfolio. Although each scenario meets the objectives of reducing water use while maintaining farmer revenues and food security, the choice of scenario adopted depends on certain political economy considerations. These are discussed in the next section. 


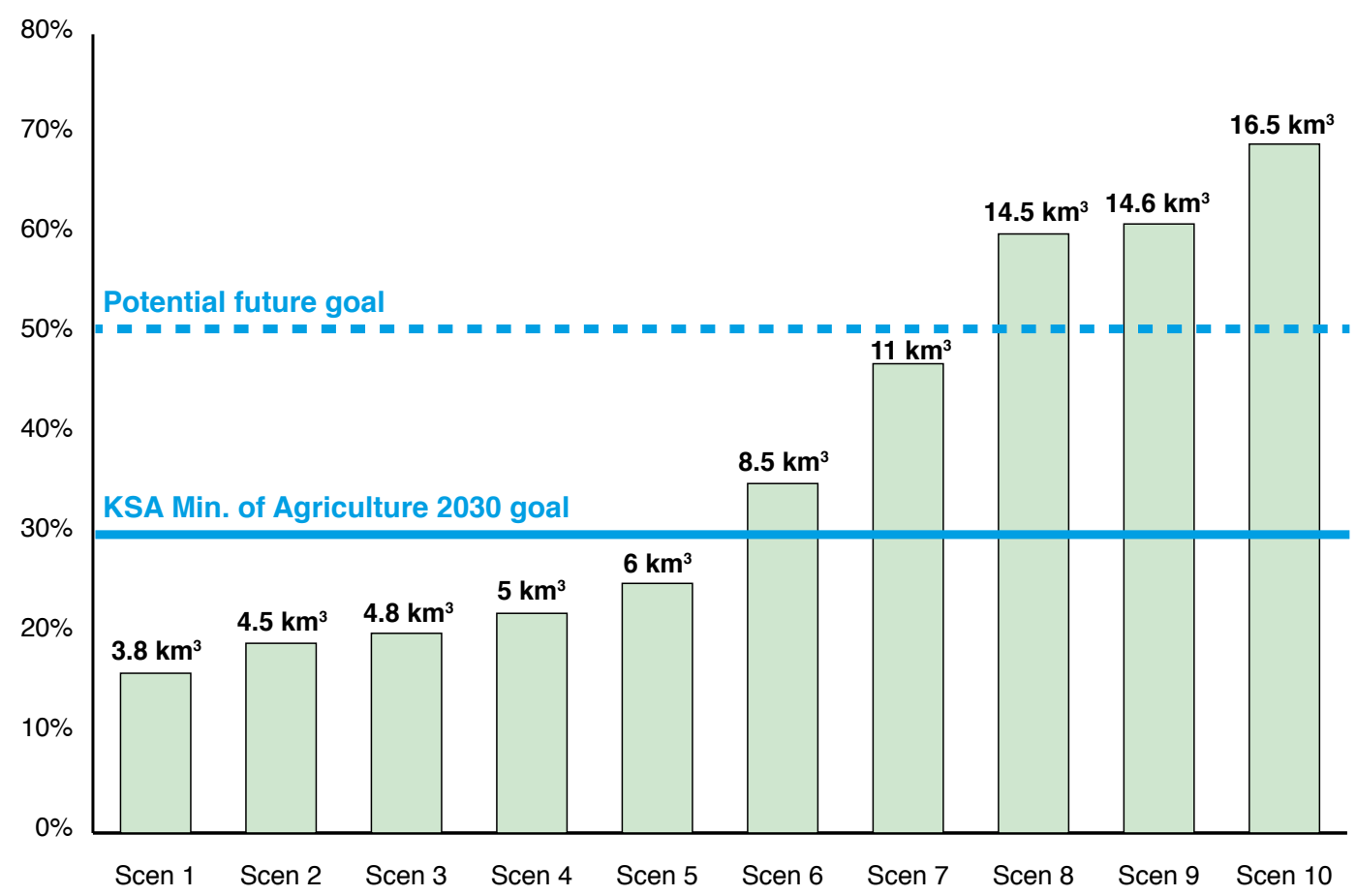

Figure 2. Potential water savings from crop switching

Source: KAPSARC analysis

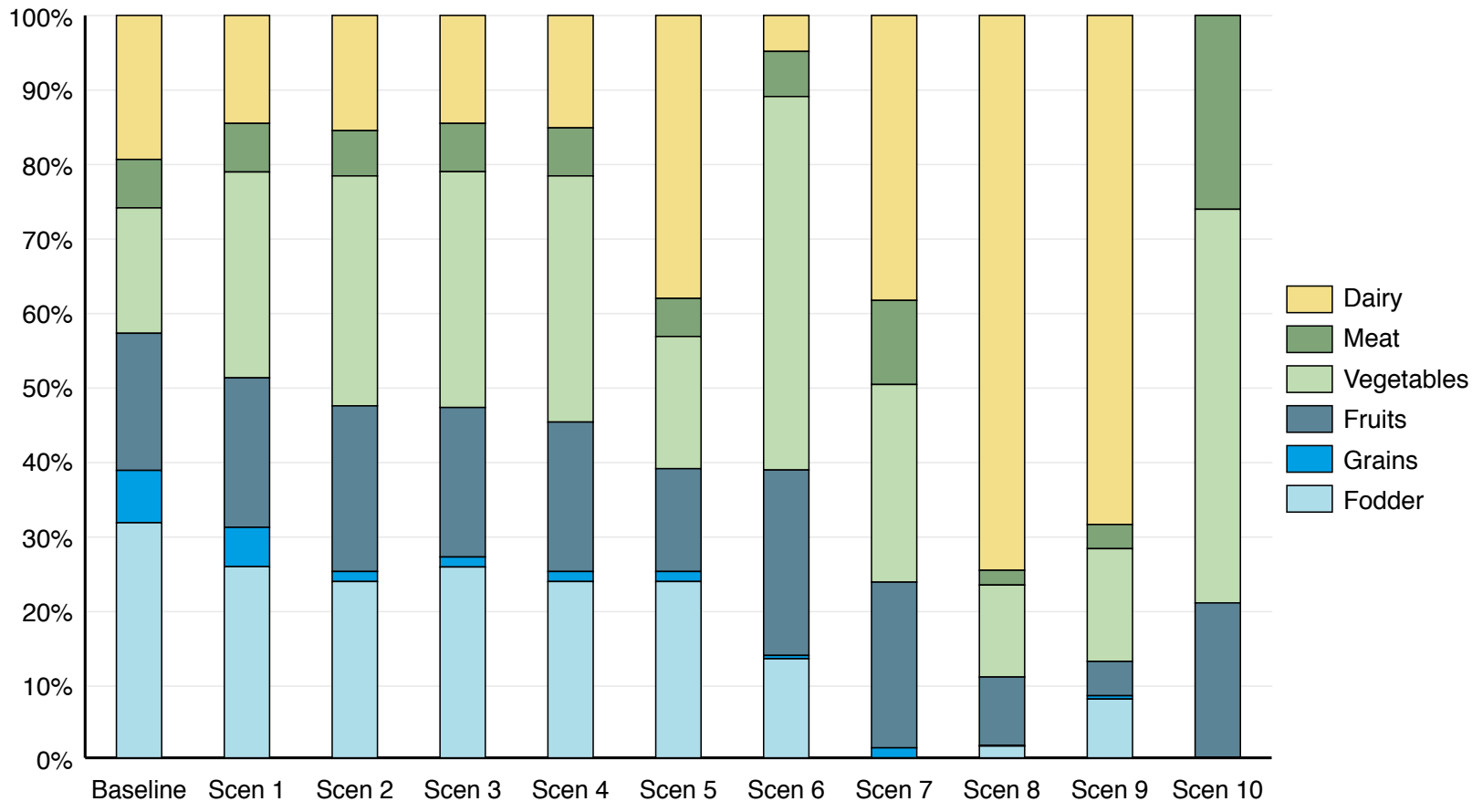

Figure 3. Crop mix from different scenarios

Source: KAPSARC analysis 
The Effects of Reduced Water Consumption on Energy Use

The potential effects of reduced water consumption on energy use depends on the source of the water being saved. Figure 4 below shows that the total energy required to extract water from the surface, ground, and desalination is just under 200,000 $\mathrm{BOE} / \mathrm{d}$. Note, in the case of ground and surface water, only energy for extraction (and not treatment) is included, and in all cases energy for water transport is not included. Thus, this figure does not include the total energy required to meet water demand in the country. Reducing water use by 16.5 $\mathrm{km} 3$, the result of scenario 10, would reduce energy consumption by roughly 40 percent. This result, however, assumes that the water reductions occur only where the water for agriculture is currently being extracted (i.e., ground and surface water). But, as the table shows, roughly half of the energy required to meet total water demand comes from the $1.3 \mathrm{~km}^{3}$ of desalination produced in Saudi Arabia. If the ground and surface water saved were used to displace a portion of the desalinated water produced in the country, far more energy could be saved from water reductions. Given the extraordinary water scarcity in the country it is likely that desalination will continue to be an important part of the water portfolio, even if agriculture production was significantly reduced. Despite this, the table shows the potential energy savings from reducing water where the marginal cost of energy is the highest.

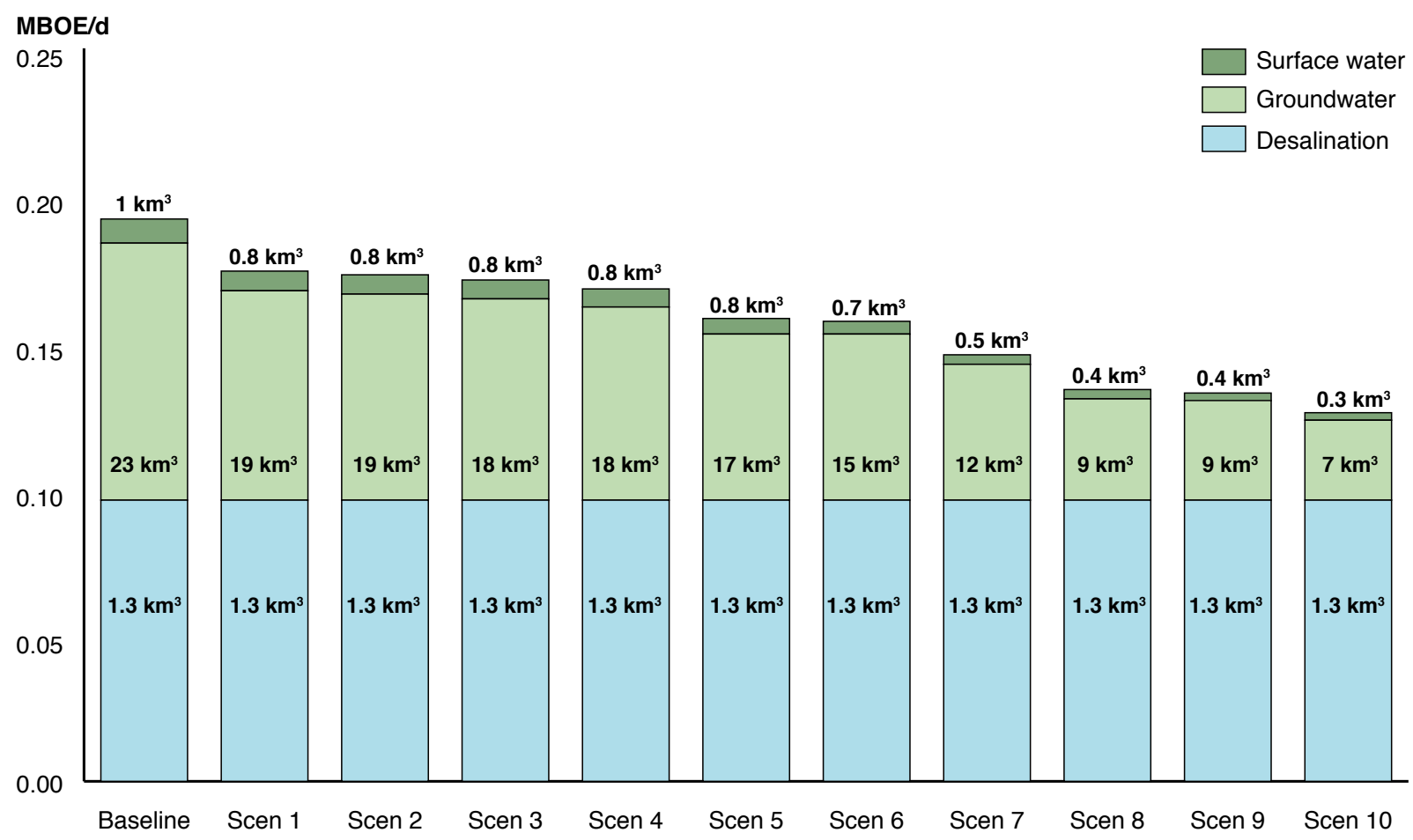

Figure 4. Potential energy savings from water reductions 


\section{Collective Choice Model}

$\mathrm{n}$ determining where to cut back or increase agricultural production, the scale of the farming of the different crops and cultural importance of certain crops are factors one would consider. We use a model that weighs a set of factors based on group decision-making models. This allows us to bring together the heterogeneous interests of the farmers of different crops to assess the values of the different scenarios. A reasonable policy choice is likely to be close to what the players would negotiate among themselves. Thus, we examine the plausibility of potential outcomes as if the farm sectors were engaged in a negotiation among themselves.

The model is described in three sections. First, the underlying theory of collective decision making is summarized. The second section describes the estimation of utility based on changes in revenue. Finally, a method for giving the sectors importance weights is presented, which forms the core of this application.

\section{Theory of Collective Choice}

Since the outcomes of group decisions often lead to winners and losers, there is no group utility function like the individual utility function of economics. This lack of utility function has led to the study of non-cooperative and cooperative game theory and literature on group choice. The formal study of group choice can be traced to Caritat, the Marquis de Condorcet, over two hundred years ago (Caritat 1785). Caritat introduced the fundamental notion of a "Condorcet Winner", which is the option the group would take over any alternative option (if every pairwise comparison can be made [options are feasible or not, not their comparisons]). A common-sense property of a person's assessments of options is that if option A is preferred to option B and option $B$ is preferred to option $C$, then $A$ should be preferred to $\mathrm{C}$. Caritat discovered that the simple "one person, one vote" system usually produces incoherent collective choices in that the group often has cyclic preferences where outcome $A$ is preferred to outcome $B, B$ is preferred to $C$ and $C$ is preferred to A: no Condorcet winner exists. Arrow (1950) extended this to Arrow's Impossibility Theorem (AIT) to state that, under a few common-sense conditions, no voting system is guaranteed to always produce non-cyclic group preferences.

Both these results, and many others of the so-called "chaos theorems" cited in Coughlin (1992), assume a model of formal, discrete ballots. They have no measure of degree of preference or of influence, and they use only qualitative, yes/no preferences. Thus, they are not directly applicable to situations where a few actors have much more power to determine the outcome than do other actors. Differing levels of influence were introduced by Hotelling (1928) and elaborated in Black (1948) and Downs (1957) under the assumption that policy choices could be represented as points on a one-dimensional scale and that the group would take the Condorcet Winner under weighted voting. These results have been generalized to multi-dimensional choices, such as the choice of multiple production targets for different agricultural sectors; technical details are presented in Appendix B. These models are idealized in that they assume deterministic voting in the sense that even a tiny advantage would guarantee victory. For example, an 11:10 committee vote would produce a clear victory for the first option, albeit by only one vote. While this is a reasonable model for formal committee votes, less formal means of influencing an outcome do not have such clear-cut results because random events and influences can always occur. For example, the relative influence of advisors might be estimated from their years of seniority or the number of followers, but such comparisons of potential influence are by no means precise. Similarly, if two competing groups spend 
\$11 million and \$10 million, respectively, to raise public awareness of an issue, the first does have an advantage, ceteris paribus, but the result would be by no means guaranteed. Such informal exertion of influence is generally called "informal voting", even though no formal system of ballots or scoring is involved. To model less-than deterministic group choices, we used the probabilistic choice model outlined in Appendix B.

\section{Utility Estimates}

The procedure above relies on estimates of the utility of each outcome to the actors. One obvious candidate for this utility function is the revenue in each agricultural sector, and the percentage revenue lost due to water reduction. To achieve the von Neumann utility scale, revenues were rescaled from raw values so that the scenario with the lowest revenue has value 0 and the best has value 1 , as in (7). Let the scaled value of scenario $s$ for actor $i$ be $V_{i}(s)$ and $R_{i}(s)$ be the raw value for scenario $s$. The index $j$ refers to the set of scenarios:

$$
V_{i}(s)=\frac{R_{i}(s)-\min _{j} R_{i}\left(s_{j}\right)}{\max _{j} R_{i}\left(s_{j}\right)-\min _{j} R_{i}\left(s_{j}\right)}
$$

As is well-known from finance, actors are always risk-averse to one degree or another when nontrivial amounts are at stake: they demand a positive risk premium to compensate for exposure to more risk, even when the expected value stays constant. It is well-known that as the risk of an investment increases, the interest rates on financing it also increase, which again reflects risk-aversion. Mathematically, this corresponds to a utility curve which is increasing, but at a decreasing rate. One simple way to model the utility function $U_{i}(s)$ is with a simple quadratic curve that matches the end points at 0 and at 1 :

$$
U_{i}(s)=1-\left(1-V_{i}(s)\right)^{2}
$$

\section{Influence Estimates}

A standard first estimate of an actor's influence/ importance to the outcome of a negotiation is the net wealth controlled by that actor. These weights are often called Negishi weights (Negishi 1972). While there is a debate as to whether these weights should be used in normative analysis, there is little debate that wealth and power are positively correlated. Therefore, we use the revenue in each agricultural sector as the initial estimate of informal importance.

In collective decision making, outcomes are uncertain because the major interactions occur informally, before formal decisions are announced. This is illustrated in stockholder votes in corporate takeovers when both sides aggressively solicit votes, even though majority rules once the votes are cast. Similarly, the outcome of informal discussions in councils might turn on the seniority and respect of various actors. The way uncertainty is reflected in modeling a negotiation is to compare the support enjoyed by two different proposals; details can be found in the appendix.

In the case of Saudi Arabia, the importanceweights have to be adjusted to reflect the national importance accorded to certain products. Because of the cultural attachment to dates, we assume that date production will probably be maintained at some level. At the time this research began, wheat production was in the process of being eliminated, suggesting a very low level of influence to protect wheat production. In the period after our analysis was complete, the intention to reduce fodder and alfalfa was announced; the significance of this sequence of events will be discussed later. We adjust the importance weights as little as possible in order to assign high plausibility to the two observed policy choices. This is entirely analogous to the procedure in econometrics 
where the model parameters are tuned so that the estimated probability of the observed economic choices are highly likely, given the fitted parameters. The algorithm seeks a minimal set of adjustments to simultaneously meet two conditions. The first condition is that, without any influence of the goal to reduce water usage, the current situation is assigned a probability above a pre-specified threshold. The second is that, with influence for water minimization, the announced policy for water minimization is also above the threshold. Results for selected crops are listed in Table 2.

\section{Evaluation of the Scenarios}

Several results stand out. The first is that the mid-range water-reduction plans are the most strategically advantageous (scenarios 4 and 7). The initial expectation was that small water reductions would be more strategically palatable than larger ones, but this turns out not to be the case. Upon examining the data set, the reasons are clear. If water usage is minimized while maintaining gross revenue and production, then the primary candidates for reduction would be those with large water usage and having low revenue or low production or both. The production of fodder for livestock fits this description. In line with policy announcements when this research began, the nominal policy case includes a constraint that sufficient fodder be produced in the Kingdom to supply the needs of livestock in the Kingdom. An alternative policy is presented which is identical except that the fodder constraint is removed, meaning that fodder is purchased from overseas. Keeping the fodder constraint does allow some water savings, but much greater savings are obtained by dropping it. Abandoning the fodder constraint means that a great deal of water can be saved with little impact on revenue. This is strongly favored by the water-minimization actor, while the additional revenue and production is favored by virtually all the actors except fodder: it produced significant gains at no cost for all actors except the weak fodder producer.

As mentioned, the influence values were estimated to meet two threshold probabilities simultaneously: a high likelihood of the current situation when water minimization was not pursued and a high likelihood of the nominal policy when water minimization is pursued. To examine the sensitivity of these results, the threshold probability of the nominal policy scenario was lowered in steps from 80 percent to 50 percent, as seen in Figure 5. In each case, moderate water savings remains the most likely result. As the distribution is flattened, the most likely policy outcome is pushed down and the secondmost likely outcome was raised, but the graph did not qualitatively change shape.

A second result is that while some of the fitted weights are roughly as expected, some are opposite the expected value, as seen in Table 2. As expected, the strength of the water reduction interest was one of the largest. Also as expected, alfalfa and other fodder were rated as weaker than their initial Negishi weights would suggest.

However, dates are fitted to be slightly weaker, while chicken meat and sheep milk are much higher. This result comes from the constraint limiting change to these products. If water were to be minimized, production of chicken meat and sheep milk would be greatly cut, but the limited-change constraint prevents that outcome. Therefore, those producers are assigned higher weight, reflecting their ability to limit the change in their production and avoid deeper cuts. 


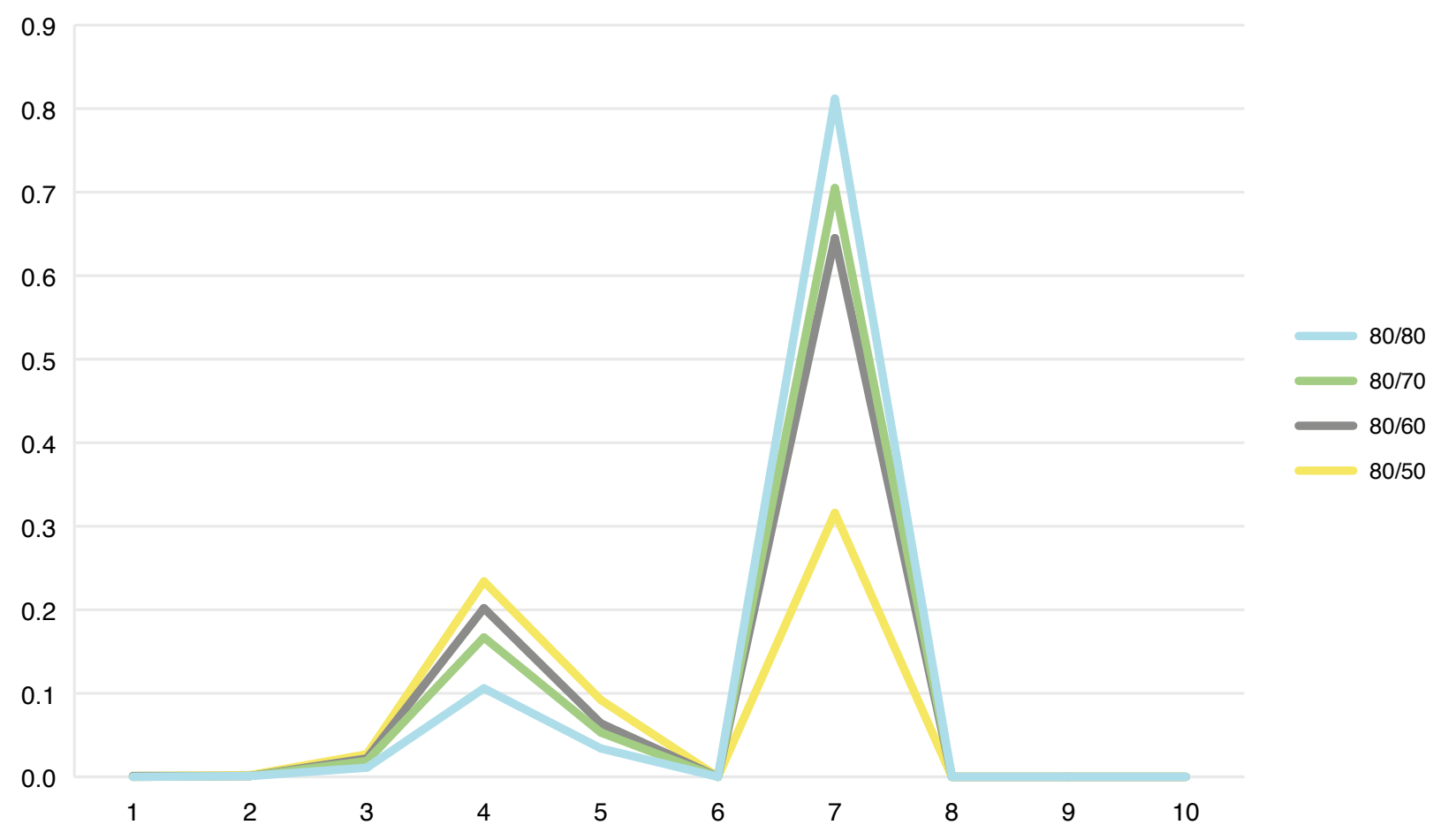

Figure 5. Sensitivity of water reduction to changes in nominal policy scenario Source: KAPSARC analysis

Table 2. Selected Negishi weights

\begin{tabular}{c|c|c} 
Group & Initial & Fitted \\
\hline Water reduction & -- & $1,114,490$ \\
Alfalfa & 744,646 & 414,950 \\
Other fodder & 369,065 & 205,660 \\
Dates & 558,531 & 311,238 \\
Milk (cow) & 602,330 & 384,328 \\
Meat (chicken) & 857,680 & $1,487,605$ \\
Tomatoes & 201,452 & 36,827 \\
Meat (cow) & 469,800 & 299,765 \\
Eggs & 199,954 & 127,584 \\
Milk (sheep) & 26,520 & $1,731,450$
\end{tabular}




\section{Conclusions}

S audi Arabia is a severely water scarce country. Much of the water extracted is used by the agriculture sector, which is seen as strategically important given the country's food security and social objectives including rural employment. This paper uses a simple linear programming model to explore the different ways water reduction objectives could be met without further compromising food security or farmer revenues. The results suggest a number of options for meeting both the 30 percent and 50 percent objectives of the Ministry of Agriculture. These outcomes are achieved by substantially reducing or eliminating certain large water intensive crops. For each option, the water cuts lead to energy savings, with the amount of energy saved being a function of where the actual water reductions occur. The water savings lead to potentially large energy savings where the ground or surface water saved is used to displace desalinated water. However, such a strategy will likely have effects on overall long-run water scarcity in the country.

We explore the potential implications of different water reduction strategies on the agricultural sectors. The results suggest that palatable options exist, with the most likely from a group negotiation being scenario 7 - eliminating fodder and wheat, significantly decreasing the production of grains, and increasing dairy, fruit, meat and vegetables which results in a 47 percent drop in water use. The Ministry of Agriculture's recent decision to phase out fodder reinforces confidence in our analysis. The findings also defy the notion that small water reductions would be more socially palatable than larger ones. If water usage is to be minimized while maintaining gross revenue and production, then the primary candidates for reduction are those with large water intensity and low revenue and/ or output. Eliminating these types of crops would actually yield higher water savings than moderate reductions across a large portfolio of crops.

The insights from this study can be extended through research on the role of input prices in the decision to produce certain crops. As discussed earlier, subsidies play a key role in Saudi Arabia's agriculture sector, effectively making the choice of which crops and livestock are produced. When policymakers seek to increase the production of certain crops, or reduce the prices paid by consumers for domestically produced crops, subsidies for these crops are raised. Policymakers have been equally proactive when subsidies have led to excessive production, as was the case with barley in the 1990s and wheat more recently. Subsidies were reduced, making them uneconomical for producers. Given this, it is the subsidy regime, and not market forces, that effectively determine quantities and prices of domestically produced agricultural products. A second-order assessment may be formulated as a mixed complementarity problem (MCP) to explore the role of input prices in crop production and, ultimately, water consumption.

\section{Last, although the Food and Agricultural} Organization has provided a good definition of food insecurity, there is no useful definition for food security at the national level. A comprehensive definition would measure the risk of shortfalls in food supply, both domestically and internationally. One component of a definition could be the level of inventory until the next harvest; another could be the risk of high costs in covering a domestic shortfall; and, still another, the threat of an embargo. Capturing the uncertainty of supply involves modeling the uncertainty of outcomes. Potentially relevant approaches include the models developed in finance or grain storage (Gustafson 1958). There is value in developing an appropriate representation of this uncertainty. 
Almarai Farming Division 2010. "Farming in the Desert [PDF slideshow]" Accessed 2015. http://www. organicpastoral.co.nz/site/organic/images/Desert.pdf

Al-Shayaa, M. S., Mizra Baig, and Gary S. Straquadine. 2012. "Agricultural Extension in the Kingdom of Saudi Arabia: Difficult Present and Demanding Future". The Journal of Animal and Plant Sciences. 22(1), 239-246. ISSN: 1018-708.

Aquastat Database. Accessed August 2015. http://www. fao.org/nr/water/aquastat/main/index.stm

Arab Organization for Agricultural Development (AOAD). 2012. "Annual Statistical Book Vol 32." Accessed 2015. http://www.aoad.org/priod en.htm

Arrow, Kenneth J. 1950. "A Difficulty in the Concept of Social Welfare." Journal of Political Economy 58(4). doi:10.1086/256963.

Arrow, Kenneth J. 1951. Social Choice and Individual Values. 1963. 2nd ed. New Haven: Yale University Press.

Bankes, Steven, and Ben Wise. 2015. Non-spatial Probabilistic Condorcet Election Methodology. http://arxiv.org/abs/1505.02509

Becker, Gary S. 1983. "A Theory of Competition among Pressure Groups for Political Influence." The Quarterly Journal of Economics 98 (3). Oxford University Press: 371-400.

Berger, James. 2010. Statistical Decision Theory and Bayesian Analysis. Springer Verlag.

Black, Duncan. 1948. "On the Rationale of Group Decision-making." Journal of Political Economy 56 (1). University of Chicago Press: 23-34.

Bradley, Ralph Allan, and Milton E. Terry. 1952. "Rank Analysis of Incomplete Block Designs: The Method of Paired Comparisons." Biometrika. 39 (3/4). 324-45. doi:10.2307/2334029.
Brown, Amber, and Marty D. Matlock. 2011. A Review of Water Scarcity Indices and Methodologies (White Paper \# 106). University of Arkansas: The Sustainability Consortium.

Bueno de Mesquita, Bruce, David Newman, and Alvin Rabushka. 1988. Forecasting Political Events: The Future of Hong Kong. Yale University Press.

Caritat, Maire Jean A. N. 1785. Essay on the Application of Analysis to the Probability of Majority Decisions.

Coughlin, Peter J. 1992. Probabilistic Voting Theory. Cambridge University Press.

Downs, Anthony. 1957. "An Economic Theory of Political Action in a Democracy". Journal of Political Economy 65 (2). University of Chicago Press: 135-50.

Enelow, James M., and Melvin J. Hinich. 1990. Advances in the Spatial Theory of Voting. Cambridge University Press.

FAOSTAT. Accessed August 2015. http://faostat.fao.org

FAO. 2001. The State of Food Insecurity in the World 2001. The Food and Agriculture Organization of the United Nations. http://www.fao.org/docrep/003/y1500e/ y1500e00.htm

Glickman, Mark E. 1999. "Parameter Estimation in Large Dynamic Paired Comparison Experiments." Journal of Applied Statistics. 48, 377-394.

Glickman, Mark E. 2001. "Dynamic Paired Comparison Models with Stochastic Variances." Journal of Applied Statistics. 28. 673-689. doi: 10.1080/02664760120059219.

Gustafson, Robert L. 1958. "Implications of Recent Research on Optimal Storage Rules". Journal of Farm Economics. 40(2): 290-300.

Hotelling, Harold. 1929. "Stability in Competition". The Economic Journal. 39: 41-57. 
Jeffreys, Andrew. 2011. The Report: Saudi Arabia. 2010 United Kingdom: Oxford Business Group.

Lippman, Thomas W. 2010. "Saudi Arabia's Quest for Food Security." Middle East Policy. 17(1).123-231. doi:10.1111/j.1475 4967.2010.00428.x

Matar, Walid, Frederick Murphy, Axel Pierru, and Bertrand Rioux. 2015a. "Lowering Saudi Arabia's fuel consumption and energy system costs without increasing end consumer prices." Energy Economics. 49, pp. 558-569.

Mekonnen, M. M., and Hoekstra, A. Y. 2012. "The Blue Water Footprint of Electricity from Hydropower." Hydrology and Earth System Sciences. 22, 123-231. doi:10.5194/hess-16-179-2012.

Merrill, Samuel, and Bernard Grofman. 1999. "A Unified Theory of Voting." Cambridge University Press.

Moench, Marcus. 2002. "Water and the potential for social instability: Livelihoods, migration and the building of society." Natural Resources Forum. 26(3). 195-204. doi: 10.1111/0165-0203.0002.

Mousa, Hussein. 2015. Grain and Feed Annual (GAIN Report No. SA1502). U.S. Embassy Riyadh: USDA Foreign Agricultural Service.

Nash, John. 1950. "The Bargaining Problem." Econometrica. 18 (2): 155-162.

Negishi, Takashi. 1972. General Equilibrium Theory and International Trade. North-Holland Publishing Company.

Persson, Torsten, and Guido Tabellini. 2002. Political Economics: Explaining Economic Policy. The MIT Press.

Poole, Keith T., and Howard Rosenthal. 1997. Congress: A Political-Economic History of Roll-Call Voting. Oxford University Press.
Poole, Keith T., and Howard Rosenthal. 2001.

"D-NOMINATE After 10 Years: A Comparative Update to Congress: A Political-Economic History of Roll-Call Voting." Legislative Studies Quarterly 26 (1).

Riker, William H. 1982. Liberalism Against Populism. Waveland Press.

Sadik, A., El-Solh, M., \& Saab, N. 2014. "Food Security: Challenges and Prospects". Arab Environment 7. http:// www.afedonline.org/Report2014/E/p01-11\%20eng\%20 preface.pdf

Sen, Amartya. 1982. "The Food Problem: Theory and Policy." Third World Quarterly. 4(3). 447-459. doi:10.1080/01436598208419641.

Shepsle, Kenneth A. 2010. Analyzing Politics. 2nd ed. W. W. Norton \& Company.

Vincent, Peter. 2008. Saudi Arabia: An Environmental Overview. Netherlands: Taylor \& Francis/Belkema.

Woertz, Eckhart. 2013. Oil for Food: The Global Food Crisis and the Middle East. United Kingdom: Oxford University Press.

The World Bank. 2015. World Development Indicators. Accessed August 2015. http://databank. worldbank.org/data/reports.aspx?Code=SP.POP. TOTL\&id=af3ce82b\&report name=Popular indicators\&populartype $=$ series\&ispopular $=y \#$

World Trade Organization. 2011. Trade Policy Review Report by the Kingdom of Saudi Arabia (Report Paper No.256).

Zermelo, Ernst. 1928. "Die Berechnung der Turnier-Ergebnisse als ein Maximumproblem der Wahrscheinlichkeitsrechnung". Mathematische Zeitschrift. 29(1). 436-460. 


\section{About the Authors}

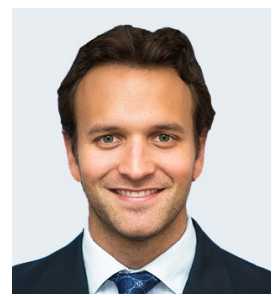

\section{Christopher Napoli}

Christopher Napoli is a research fellow focusing on natural resource economics and energy policy. He holds a PhD from the University of Kent, U.K.

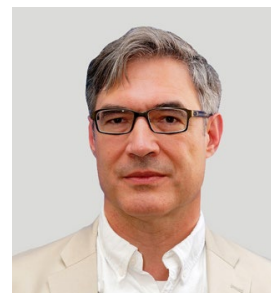

\section{Ben Wise}

Ben Wise, $\mathrm{PhD}$, is a senior research fellow working on models of collective decision making in the Human Geography of Energy Program.

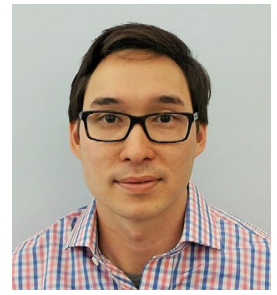

\section{David Wogan}

David Wogan is a research associate developing energy systems models. He holds master's degrees in mechanical engineering and public affairs from UT Austin, U.S.

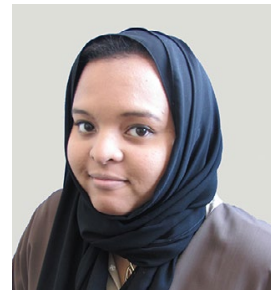

\section{Lama Yaseen}

Lama Yaseen is a research analyst focusing on energy politics. She holds a BSc in Computer Science from Effat University in Jeddah, Saudi Arabia.

\section{About the Project}

This project explores how crop substitution can reduce aggregate water use without compromising food security or farmer revenues in Saudi Arabia. The potential effects of crop substitution on total water use, total energy used to meet water demand, and the diversity of crops produced are examined. Additionally, a political bargaining model that estimates the balance of influence of actors affected by crop substitution is developed. The project is part of a larger body of KAPSARC research on the water-energy-food nexus. 


\section{Appendix A}

Table A-1. Data input for linear programming model

\begin{tabular}{|c|c|c|c|}
\hline Crop & Initial Production (tons) & Water Footprint (m³/ton) & Revenue (1000 USD/ton) \\
\hline Alfalfa & $2,659,449$ & 2223 & 0.275 \\
\hline Barley & 11,267 & 1544 & 0.119 \\
\hline Cabbages & 7,822 & 183 & 0.15 \\
\hline Carrots & 56,121 & 427 & 0.249 \\
\hline Citrus & 99,019 & 4281 & 0.452 \\
\hline Cucumbers & 246,986 & 137 & 0.199 \\
\hline Dates & $1,095,158$ & 3059 & 0.511 \\
\hline Eggplants & 59,023 & 634 & 0.214 \\
\hline Eggs & 240,908 & 334 & 0.829 \\
\hline Fresh fruits & 360,000 & 4753 & 0.349 \\
\hline Gourds & 119,873 & 646 & 0.175 \\
\hline Grapes & 134,484 & 1448 & 0.572 \\
\hline Honey & 108 & 0 & 2.509 \\
\hline Maize & 95,356 & 3556 & 0.142 \\
\hline Meat (camel) & 22,552 & 427 & 2.096 \\
\hline Meat (chicken) & 604,000 & 502 & 1.424 \\
\hline Meat (cow) & 174,000 & 631 & 2.701 \\
\hline Meat (goat) & 3,334 & 276 & 2.396 \\
\hline Meat (sheep) & 16,277 & 375 & 2.723 \\
\hline Melons & 230,246 & 549 & 0.184 \\
\hline Milk (camel) & 105,000 & 330 & 0.341 \\
\hline Milk (cow) & $1,943,000$ & 330 & 0.312 \\
\hline Milk (goat) & 80,000 & 330 & 0.336 \\
\hline Milk (sheep) & 68,000 & 594 & 0.389 \\
\hline Millet & 4,486 & 4848 & 0.181 \\
\hline Nuts (ground) & 2,050 & 1457 & 0.451 \\
\hline Okra & 44,454 & 398 & 0.639 \\
\hline Onions & 112,478 & 243 & 0.21 \\
\hline Other Fodder & $1,318,090$ & 1887 & 0.275 \\
\hline Potatoes & 390,259 & 524 & 0.169 \\
\hline Pulses & 14,000 & 3374 & 0.556 \\
\hline Sesame seeds & 2,487 & 6568 & 0.677 \\
\hline Sorghum & 110,299 & 3420 & 0.154 \\
\hline Tomatoes & 544,464 & 338 & 0.37 \\
\hline Vegetables & 526,408 & 761 & 0.188 \\
\hline Watermelons & 401,058 & 407 & 0.114 \\
\hline Wheat & 660,145 & 2233 & 0.158 \\
\hline
\end{tabular}




\section{Deterministic Collective Choice Model}

We represent the collective decision making process as probabilistic, informal "voting" over a set of policy choices. The policy choices in this case are the target production quantities. The methodology is motivated first by looking for a simple equilibrium. It is natural to expect interest groups to exert influence proportional to two factors: how strong they are, and how much is at stake for them. For brevity, each interest group is called an "actor" and the whole group of actors called "the group". Actors are generally indicated by a simple numerical index, like $i, j$, or $k$. An actor's influence is denoted by $w_{i}$. A common measure of influence exerted in a formal democratic vote is the number of votes cast in an election, where the weight of each voting bloc is $w_{i}$, the number of voters in that block. A common measure of informal influence exerted is the amount of money available to influence public opinion. If the utility to actor $i$ of production level $q$ is $U_{i}(q)$, then the amount at stake for a small increase in $q$ is simply the derivative of $U_{i}$ with respect to $q$. Suppose that a second actor $j$ is also affected by the choice of $q$, as might happen when there is a production or revenue constraint affecting both actors. Suppose that $i$ would rather see $q$ increased, while $j$ would rather see it decreased, the expected marginal change in votes would depend on both the size of the voting block and the difference in utility between two closely spaced options. If each actor exerts influence proportional to these two factors, influence and stakes, then the level of $q$ increases if the following quantity is positive:

$$
w_{i} \frac{\partial U_{i}}{\partial q}+w_{j} \frac{\partial U_{j}}{\partial q}
$$

It is important to note that this is not the sum of interpersonal utilities. If the measure of influence exerted is votes, then each term represents the marginal shift in the expected number of votes between two closely spaced options. The amount of influence actually exerted and the motivation to do so are closely correlated, but they are quite different things: votes are not desires. While adding up interpersonal utilities would not make sense, adding up the number of votes cast is quite feasible.

Similarly, the balance of influence drives the group choice of $q$ down whenever the above quantity is negative.

The condition that a stable balance of influence should prevail is simply that this weighted sum of derivatives is zero, and that the second derivative is negative. This is the familiar condition for the maximum of a function:

$$
\zeta(q)=\sum_{i} w_{i} U_{i}(q)
$$

The expected outcome is the $q$ that achieves a balance of influence, i.e. that maximizes $\zeta(q)$. Again, it is extremely important to understand that this is not the weighted average of utilities, even though differences in utility are highly correlated with differences in influence exerted. If the measure of influence exerted is the number of formal votes cast in a legislature, then this result is just a formal restatement of the idea that the option with the most votes wins. This particular functional form can be derived from several theoretical perspectives. This is same maximization, which appears in the Luce binary voting model, Coughlin (1992), though the Luce model requires very restrictive conditions to apply. The maximum of this function is also identified as the political equilibrium, under a different set of restrictive assumptions, in Becker (1983). A much more broadly applicable derivation appears in Bankes (2015). 
One early and thorough discussion of this function appears in Arrow (1951). In particular, Arrow stated that it meets all his common-sense conditions for a fair and consistent social choice function except for two. First, the AIT is perfectly egalitarian in that it requires all actors to be treated symmetrically, thus ruling out the possibility of considering voting blocs with different $w_{i}$. In some practical situations, a particular actor might have vastly more weight than others, and could completely determine the outcome if they chose to do so. In most situations, identifiable interest groups do exist (such as the agricultural and environmental interests considered in this paper). They have different levels of importance and influence, and they compete with each other to influence the outcome of the group choice - possibly by formulating and presenting proposals to more powerful actors. Further, AIT prohibits the actors from having any intensity of preference between options. For example, this means that in Arrow's scheme there is no way to represent the concept of an actor compromising over minor differences to avoid a major conflict, because there is no way to express the concepts of "minor" or "major" preferences. Of course, Arrow clearly distinguishes the influence exerted by actors (e.g. votes or money, which can be compared and summed) from the motivations of those actors (e.g. utilities, which cannot be compared or summed).

These results allow us to treat (9) as a value function for the group with the weights representing the relative contribution of the members to the value of the group choice.

\section{From Deterministic to Probabilistic Choice Models}

The deterministic negotiation model is transformed into a stochastic model by treating the choice as a random walk. When there is a choice between two values, say $q_{1}>q_{2}$, then the influence exerted to increase $q$ is again proportional to strength and stakes. Designate as $C_{12}$ the set of actors who would like to see $q$ increased to $q_{1}$ (versus $q_{2}$ ):

$$
C_{12}=\left\{i \mid U_{i}\left(q_{1}\right)>U_{i}\left(q_{2}\right)\right\}
$$

As with the deterministic, continuous case, the strength of this implicit coalition would be just the total influence each member would exert:

$$
S_{12}=\sum_{i \in C_{12}} w_{i}\left(U_{i}\left(q_{1}\right)-U_{i}\left(q_{2}\right)\right)
$$

As discussed for the deterministic case, the sum of informal votes is the sum of influences, not of interpersonal utilities. For example, we would compare the total votes cast without comparing the motivation for those votes.

Similarly, an opposing coalition would like to see a reduction to $q_{2}$ (versus $q_{1}$ ). This coalition is designated $C_{21}$ and its strength is designated $S_{21}$.

The standard model for estimating the likelihood that one actor prevailing over another was first presented in Zermelo (1928), though it is often attributed to Bradley (1952). It has been used extensively to estimate the strength of both individual and team competitors Zermelo (1928), Glickman (1999; 2001). Applied to our problem of choosing between two policies on production quantities, the probability that $q_{1}$ will be chosen over $q_{2}$ depends simply on the relative strength of each coalition:

$$
P\left[q_{1}>q_{2}\right]=\frac{s_{12}}{s_{12}+s_{21}}
$$

The probabilistic choice model has been used quite successfully to analyze political decision making by de Mesquita (1988), Poole (1997; 2001). This probabilistic relationship gives a biased random walk, which tends to cluster at the maximum of $\zeta$. 
Notes

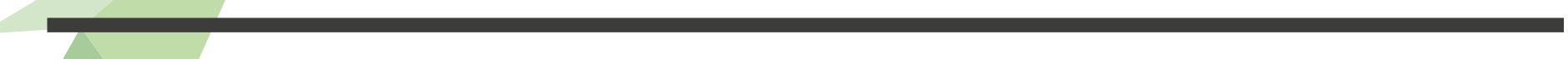




\section{Notes}

(1) 
Notes

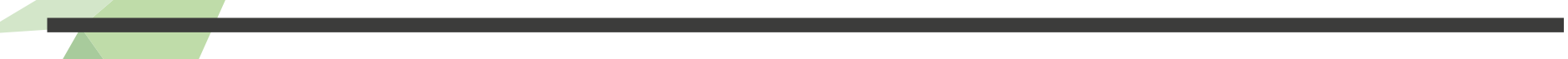


INAPSARC

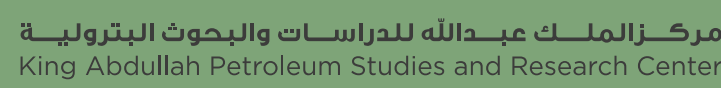

www.kapsarc.org 